\title{
O trabalho como determinante do processo saúde-doença
}

\author{
Ana Claudia Moreira Cardoso
}

Uma vivência do trabalho no contexto atual

Este artigo se inicia com o relato de uma trabalhadora do setor bancário que está em licença para tratamento de saúde há dois anos e cinco meses ${ }^{1}$.

Paula sempre quis ser superintendente e, para isso, investiu muito em sua formação. A bancária realizou cursos de marketing na Escola Superior de Propaganda e Marketing (ESPM), de recursos humanos no Instituto Brasileiro de Mercado de Capitais (Ibmec), de especialização na área de finanças na Universidade Estadual de Campinas (Unicamp) e de pós-graduação em

1. Essa narrativa foi construída com base no relato de uma trabalhadora bancária no I Seminário Internacional de Análise e Prevenção de Acidentes no Trabalho (Sipat), que ocorreu na cidade de São Paulo de 26 a 29 de agosto de 2014 . gestão empresarial na Fundação Getúlio Vargas (FGV). Praticamente todos eles foram financiados pela trabalhadora, e, sempre que ela acabava um curso, o seu coordenador lhe dizia: "Ótimo, qual será o próximo?”.

No seu trabalho, cada vez que ela conseguia alcançar um bom resultado em uma agência, seu chefe a mandava para outra agência, considerada problemática, para torná-la rentável e com resultados positivos. Além disso, Paula relata que tinha um número cada vez maior de clientes. Pouco antes da sua licença, era responsável pela folha de pagamento de 267 grandes empresas, além de gerenciar cerca de quatrocentos funcionários, sendo 72 gerentes diretos; ou seja, ela era a responsável por qualquer problema com um desses clientes e/ou trabalhadores. Como "reconhecimento" pelo seu bom trabalho, mediante o alcance das metas, ganhava cada vez mais clientes em mais estados para administrar, não tendo 
mais tempo "para sequer almoçar, nem responder e-mails". Muito menos para sua família e amigos.

Foi quando deslocaram Paula para trabalhar no Rio Janeiro, na época da implantação das Unidades de Polícia Pacificadora (UPPs). O motorista que a acompanhava até o trabalho várias vezes ia à frente, para ver se era possível entrar nas agências em que ela trabalhava, localizadas nos morros do Jacaré, Macaco e Borel. Paula, ao voltar para o hotel em que se hospedava, estava esgotada e ainda tinha todos os e-mails do dia para responder, somar a produção diária, cobrar os que deixaram de fazer, entre outras pendências.

Ela se sentia muito cansada, com fadiga, dores de cabeça, no ombro, tontura e "vontade de sumir", confessando ter desejado se jogar do $27^{\circ}$ andar do luxuoso hotel Othon. Mas queria se mostrar firme e precisava atingir a meta, ou seria humilhada na reunião semanal do banco. "Eu alcançava todas as metas impostas, sei que consegui fazer muito resultado para o banco. Mas também foi assim que o banco foi tirando as horas da minha vida e da minha família. Eu não tinha mais tempo para nada. Fui sentindo que minha energia estava acabando".

Cansada de tudo e não vendo mais saída, Paula tirou licença para realizar uma cirurgia da bexiga, que já era solicitada por seu médico há três anos e, por conta da carga de trabalho, não conseguira fazer. Quando se afastou para realizar o procedimento cirúrgico, a bancária passou a ser atendida apenas pelo departamento de recursos humanos do banco e a receber números de protocolos. Tal situação, agravada por seu histórico no trabalho, a deixou transtornada: "meu cérebro entrou em pane mental, tive um branco, tive surto e síndrome do pânico. Naquele momento, me levaram a um psiquiatra, que detectou que eu estava com estresse profundo, correndo risco de a minha mente nem se recuperar". A Comunicação de Acidente de Trabalho (CAT) foi aberta pelo sindicato dos Bancários de São Paulo e, ainda assim, o banco informou ao Instituto Nacional do Seguro Social (INSS) que não tinha recebido o documento.

Paula relata tristemente suas idas aos peritos do INSS, um ortopedista, outro otorrino. "Nenhum quis ouvir o que eu tinha para contar, minha experiência no trabalho, meus sintomas e minhas dores: os médicos não consideram o que os trabalhadores falam”. Até que, numa terceira perícia, ela começou falando à médica que, se não pudesse novamente contar o que estava sentindo e o que estava acontecendo, iria embora e desistiria. Nesse momento, a médica se propôs a ouvi-la e explicitou que não conhecia muito sobre adoecimento mental ou, especificamente, sobre a Síndrome de Burnout, mas solicitou que Paula deixasse com ela o material sobre o assunto para que pudesse pesquisar. 
Da parte da empresa, explicita Paula, silêncio total. Nenhum telefonema. Até hoje a CAT não foi aberta, e ela permanece licenciada em função da sua cirurgia na bexiga e não do adoecimento mental. Entretanto, o diagnóstico de Burnout foi dado por dois médicos psiquiatras. "Hoje em dia, eu nem consigo passar na frente do banco", afirma Paula.

Após o diagnóstico, Paula tentou tratamento com vários remédios: Venvance, Dormonid, Dalmadorm, Frontal XR, Lyrica, Aropax, Razapina e Quetiapima, que desencadearam efeitos colaterais, como melancolia e diminuição do desejo sexual. Isso se refletiu em seu relacionamento familiar, tanto emocional como financeiro. Afinal, a conta mensal com remédios chega a $\mathrm{R} \$$ 600 mensais. Desde que iniciou o tratamento, houve pouca melhora, e alguns medicamentos passaram a ser ministrados em doses elevadas. No que se refere aos impactos na família, eles vão ainda mais longe; uma de suas filhas tentou o suicídio, dizendo que não aguentava mais ver a mãe sem reagir e cada vez mais debilitada. "Ela é muito jovem e não conseguiu entender que eu não tinha condições de reagir, mesmo com os remédios”, relatou Paula.

Um dos últimos incidentes antes de sua licença ocorreu na noite anterior à visita a um cliente - que ela faria com seu coordenador e um gerente -, quando recebeu um e-mail contendo um relatório, às $22 \mathrm{~h}$. No dia seguinte pela manhã, a primeira coisa que ele lhe perguntou foi se ela havia lido o relatório. Diante da resposta negativa, conta que foi "destruída e criticada durante trinta minutos”. À noite, quando enfim conseguiu ler o relatório, Paula viu que era uma avaliação de desempenho e que ela era a funcionária mais bem avaliada!

Para demonstrar que a extrema pressão é sentida por grande parte dos funcionários, ela conta que em julho uma amiga do banco lhe telefonou e disse que não aguentava mais o trabalho, a pressão da supervisão, as dores e o mal-estar; disse que estava pensando em pedir demissão e gostaria de saber se Paula aceitaria abrir com ela um negócio próprio. O problema é que, duas semanas depois, a amiga teve um acidente vascular cerebral (AVC) e permanece incapacitada até hoje. Assim, Paula termina seu relato: "eu não nasci assim, eu adoeci. O banco foi me sugando".

A fala de Paula fornece elementos para a realização de diversas reflexões relacionadas com a saúde do trabalhador: a relação entre a atividade do trabalho e a saúde, os impactos do adoecimento na família, a forma como a sociedade lida com o adoecimento mental, a vivência do trabalhador em relação ao processo de adoecimento, o processo de perícia do INSS, entre outros.

Este artigo abordará preferencialmente o impacto do trabalho no processo saúde-doença. Assim, o objetivo será analisar como, no contexto atual, as 
2. Este artigo resulta de algumas experiências profissionais complementares. Como assessora e professora da Escola Dieese de Ciências do Trabalho tive contato permanente com trabalhadores e dirigentes sindicais. Participei, durante a realização de meu pós-doutorado, no Centre de Recherches Sociologiques et Politiques de Paris (Cresppa), do grupo de trabalho da Direction de l'Animation de la Recherche, des Études et des Statistiques (Dares), cujo objetivo é elaborar uma pesquisa sobre riscos psicossociais no trabalho, na França, a ser levada a campo em 2015. Outra experiência relevante foi a participação no grupo criado por Marie Pezé, psiquiatra e responsável pelos departamentos de sofrimento no trabalho de alguns hospitais franceses. $\mathrm{O} \mathrm{ob}-$ jetivo do grupo é discutir os casos atendidos por Pezé, e dele fazem parte sociólogos, advogados, psicólogos, médicos e inspetores do trabalho. Tais experiências são reveladoras da forma como se dá a relação entre o trabalho e o processo de adoecimento do trabalhador. condições organizacionais e físicas do trabalho, as situações e as relações de trabalho e as formas de gestão determinam e contribuem para o adoecimento dos trabalhadores ${ }^{2}$.

Para tanto, será buscado um diálogo entre a fala de Paula e alguns estudos teóricos que tratam da relação entre a atividade do trabalho e a saúde do trabalhador. Além disso, serão utilizados alguns dados referentes ao adoecimento no Brasil e as informações teórico-metodológicas de algumas pesquisas internacionais cujo foco é a saúde do trabalhador e/ou as condições do trabalho. Ou seja, uma análise que pretende estabelecer um contato entre as vivências individuais, as discussões coletivas e institucionais e as macroinformações sobre o assunto, dada a complexidade de compreender a relação entre trabalho e a saúde do trabalhador.

\section{O trabalho como determinante do processo saúde-doença do trabalhador}

Recorrer ao relato de uma trabalhadora sobre seu processo de adoecimento no trabalho parte do pressuposto de que, para compreender a relação entre trabalho e saúde, é necessário basear-se na vivência do sujeito. É ele que realiza o trabalho; é dele que se exige o empenho para fazer o trabalho; é ele quem analisa as condições que tem para realizá-lo; é ele que sofre o desgaste físico, mental e emocional; é ele que, por fim, adoece, sofre acidentes e morre (Dejours, 2007; Gollac, 2011; Cardoso, 2014). Portanto, se a pretensão é saber de que modo o trabalho está adoecendo os trabalhadores e as trabalhadoras, é preciso que sejam ouvidos e possam relatar como estão vivenciando o trabalho, como conseguem responder ou não às demandas e, por outro lado, como as empresas estão ou não dando condições para que possam realizar o que lhes é demandado. Esse papel poderia ser assumido pelas comissões de saúde no local de trabalho, pelos sindicatos, pelos médicos das empresas ou, fora destas, pelos inspetores do trabalho. Na França, por exemplo, em alguns hospitais públicos há um departamento chamado "Sofrimento no Trabalho", que tem como objetivo exclusivamente atender os trabalhadores que julgam ter adoecido em função do trabalho (Pezé, 2008).

O relato de Paula, por exemplo, evidencia algumas dimensões do trabalho que têm contribuído para o adoecimento dos trabalhadores no contexto atual. (É importante salientar que a categoria "trabalho" tem um significado abrangente, que engloba as formas de organização do trabalho, de gestão, o processo de trabalho, suas situações e condições, as relações sociais, o ambiente e uma ampla gama de outros condicionantes.) Sua fala destaca um nível extremamente 
elevado de exigência do ponto de vista físico e mental. Ela conta que trabalhava muitas horas, tanto no banco como com os clientes, o que significava muitas horas fora da sua casa. Na realidade, a demanda das empresas tem sido, cada vez mais, para que os trabalhadores estejam totalmente à sua disposição. Assim, se por um lado verifica-se, mundialmente, uma redução da jornada formal de trabalho (Lee, 2009), por outro, é possível observar as estratégias criadas pelo capital para continuar a ter os trabalhadores à sua disposição, seja por meio da flexibilização do tempo de trabalho, seja por sua ampliação velada, possibilitada por toda a tecnologia de comunicação (Cardoso, 2009). O mais grave é que esse tempo dedicado ao trabalho não é contabilizado como parte da jornada. O episódio do relatório enviado a Paula às $22 \mathrm{~h}$ e cuja leitura lhe foi cobrada às $8 \mathrm{~h}$ do dia seguinte reflete bem essa realidade. Evidentemente, a demanda para que os trabalhadores estejam constantemente conectados à empresa tem impactos diretos na sua saúde e na de seus familiares.

Outro aspecto relevante no caso de Paula foi o aumento da carga emocional com a sua crescente responsabilização e com mudanças constantes no seu trabalho - agências, clientes, colegas, unidades da federação, processos de trabalho. Metzger (2010) ressalta que o fato de o trabalhador ter de enfrentar situações novas cotidianamente tem impactos negativos para a sua saúde mental, pois requer o aprendizado do novo em um contexto no qual não se tem tempo sequer para realizar o já conhecido. Gera insegurança e incerteza em relação ao futuro próximo e distante, além de medo, perda de referências e ainda a constante desvalorização do conhecimento adquirido. Esta, por sua vez, pressiona o trabalhador para investir cada vez mais tempo em formação, fora do seu tempo e local de trabalho, para tentar dar conta das novas situações a enfrentar.

A questão do reconhecimento é outro elemento importante, e exerce um forte impacto no processo saúde-doença (INRS, 2010). Em um primeiro momento, receber uma carga de trabalho nova e maior é visto como reconhecimento, sobretudo porque muitas vezes é acompanhada de promoções financeiras. Paula explicita, no começo de sua fala, que sempre quis ser gerente; no entanto, conta que após adoecer não recebeu nenhum telefonema da empresa ou qualquer tipo de suporte, e que isso a deixou muito triste. Ela fala, ainda, sobre o seu constante investimento em formação, sobre o qual a coordenação lhe dizia que não era mais do que a sua obrigação. $\mathrm{O}$ mesmo juízo vale para as metas que eram invariavelmente atingidas.

Muitas empresas consideram o estresse um fator estimulante, necessário para fazer com que os trabalhadores invistam cada vez mais e de forma mais 
rápida. Por isso mesmo, a gestão por metas ou objetivos tem sido comumente chamada de gestão "by stress" (Cataldi, 2011), contribuindo para o processo de intensificação do tempo de trabalho e, consequentemente, para o adoecimento dos trabalhadores. São diversos os estudos que já têm apontado a gestão por metas ou objetivos como uma fonte importante de adoecimento, tanto pela competição que pode ser gerada entre os trabalhadores como pela própria desconsideração do bem-estar a fim de atingir os resultados (Pina e Stotz, 2011; Corrêa e Lima, 2006; e Mathieu e Gorgeu, 2009). Em função disso, a combinação do comprometimento com o grupo, do desejo de aumentar a remuneração, de ter uma promoção ou o medo de perder o emprego é tão grande que os trabalhadores desconsideram mal-estares e escondem doenças ou pequenos acidentes (Askenazy, 2005).

Mesmo considerando que nem todos os trabalhadores reagem da mesma maneira ou são afetados pelas mesmas questões ou que isso ocorra no mesmo momento, o caso aqui discutido demonstra muito bem o que vem ocorrendo. Além disso, diversos estudos sociológicos e epidemiológicos confirmam que é possível verificar que há algumas situações (dentro e fora do local de trabalho) com probabilidade muito maior de desencadear uma resposta de estresse (Legeron, 2001). Esses estudos explicitam também que essas situações são vivenciadas diferentemente em função dos "meios" que os sujeitos têm para enfrentá-las e que a sua ação e reação dependem, ainda, da duração do evento (Rivolier, 1989).

Essa constatação é importante para não se correr o risco de individualizar o processo de adoecimento, que, na maior parte das vezes, tem como consequência a culpabilização dos trabalhadores e a não discussão do trabalho (Maeno e Pararelli, 2013). Nessa linha, tem se modificado a própria noção de estresse: se, antes, prevalecia o entendimento de que resultava apenas da relação entre as demandas e as capacidades do indivíduo, hoje, admite-se que a situação é estressante quando há um sentimento de desequilíbrio entre o que é demandado pela empresa e os recursos que ela torna disponíveis para que os trabalhadores respondam à demanda - sejam recursos cognitivos, de autonomia, apoio, tempo etc. (INRS, 2010). Assim, o estresse passa a ser visto não como o revelador da fragilidade dos indivíduos, mas como uma manifestação do mau funcionamento e da desorganização das empresas. São previstas ainda situações de trabalho potencializadoras e desencadeadoras do estresse e, consequentemente, do adoecimento. Entre elas, há aquelas referentes ao conteúdo do trabalho, como as fortes exigências quantitativas (carga de trabalho, pressão temporal, muita informação); qualitativas (precisão, 
qualidade, vigilância), dificuldades ligadas às tarefas (monotonia, repetição, fragmentação, ausência de autonomia) e os riscos inerentes à execução da tarefa (risco de vida, prejuízo financeiro). Em relação à organização do trabalho, os elementos desencadeadores são: falta de controle sobre as tarefas; imprecisão em relação a elas; dúvidas sobre a avaliação; contradição entre as exigências do posto; inadequação entre horário de trabalho e ritmo biológico, vida social e familiar; fluxo tenso; polivalência e instabilidade. No que diz respeito à relação de trabalho, observam-se a falta de apoio, o autoritarismo e a ausência de participação, além de causas relacionadas com o ambiente físico e o ambiente socioeconômico da empresa (Idem).

Do "individual" ao social

A complexidade da relação entre trabalho e saúde do trabalhador explicita que, para sua compreensão, a análise deve levar em conta outras fontes de informação, vindas de dentro e de fora da empresa. No primeiro caso, como sugerido pelo INRS (2010), as dimensões a serem analisadas seriam: tempo de trabalho (normal e extraordinário), rotatividade, relações sociais na empresa, tipo de formação dada aos trabalhadores e gestores, remuneração, plano de cargos e carreiras e organização do trabalho. Como "indicadores de resultado sobre a saúde”, são definidas outras informações a analisar, como o número de afastamentos ligados à saúde, o percentual de pessoas afastadas, os setores mais afetados, os motivos e a duração dos afastamentos, as visitas aos médicos do trabalho, a taxa de absenteísmo, entre outras.

Esse olhar amplo permite que sejam analisadas não apenas as consequências, mas também os determinantes do adoecimento e dos acidentes de trabalho. O problema é que, no Brasil, raramente os membros das comissões de saúde ou os sindicatos - aliás, nem mesmo os inspetores do trabalho - têm acesso a essas informações. Afinal, o local de trabalho é visto como algo privado, onde nem os representantes dos trabalhadores e do Estado podem intervir, sobretudo quando o assunto diz respeito às formas de organizar e gerir o trabalho.

Por isso mesmo é necessário destacar a importância de pesquisas nacionais que captem informações de diversos setores da economia e sejam realizadas ao longo do tempo; que possibilitem identificar as condições, organizações, tecnologias e relações de trabalho que determinam a carga de trabalho física, emocional e psicológica, a partir da vivência e da percepção daquele que suporta tal carga, o trabalhador. No Brasil, ainda não há uma pesquisa com essas características. A investigação realizada pelo Instituto Brasileiro de Geografia 
3. Os itens pesquisados por Dal Rosso (2008) foram: alongamento da jornada de trabalho, acúmulo de tarefas, polivalência, versatilidade e flexibilidade, ritmo e velocidade e gestão por resultados.

4. Essa pesquisa foi realizada com trabalhadores dos bancos Itaú Unibanco, Santander, HSBC, Caixa Econômica Federal, Bradesco e Banco do Brasil, incluindo uma fase qualitativa $\mathrm{e}$ uma quantitativa. e Estatística (IBGE) capta apenas as doenças da população, mas não questiona sobre o trabalho e o emprego dos pesquisados e, consequentemente, fica impossibilitada de estabelecer essas relações.

Em uma das raras pesquisas sobre a intensidade do trabalho, Dal Rosso (2008) revela que, para 43,2\% dos trabalhadores entrevistados, o trabalho foi mais intenso nos últimos anos ${ }^{3}$. Se focalizarmos uma das formas de intensificação, como a gestão por metas e objetivos, o percentual de trabalhadores que declara sentir uma pressão maior no trabalho é de $56,8 \%$, sendo muito diversa a situação nos diversos setores pesquisados. No setor bancário e de telecomunicação, $98 \%$ dos trabalhadores frisam o aumento de pressão em função da gestão por metas/objetivos. Além disso, o autor sublinha que, pelo fato de o trabalho exigir resultados materiais e imateriais e demandar que o trabalhador empenhe cada vez mais energia física, mental e emocional, novos problemas de saúde somam-se aos antigos. Conforme seu estudo, 24,6\% dos trabalhadores declararam já terem tido problemas de saúde decorrentes do trabalho e 18,9\% afirmaram já terem obtido atestado médico em decorrência de sobrecarga no trabalho (Dal Rosso, 2008).

No caso do setor bancário, do qual Paula faz parte, o sindicato realizou uma ampla pesquisa, em $2011^{4}$, em que ficou explícito que a pressão no trabalho, as metas abusivas e o medo de perder o emprego têm levado ao adoecimento dos trabalhadores.

84\% [dos trabalhadores pesquisados] relataram já ter sentido algum problema de saúde com frequência e acima do normal. E no ranking desses problemas, o estresse ocupa o primeiro lugar, apontado por $65 \%$ dos entrevistados. Mais da metade (52\%) disse ter dificuldade para relaxar e está sempre preocupado com o trabalho. Cansaço e fadiga constantes foram apontados por $47 \%$ deles, e $40 \%$ afirmaram sentir dor ou formigamento nos ombros, braços e mãos. Para eles o trabalho é fonte de apreensão constante e medo da exposição pública; de tensão permanente por medo de assalto e violência; é um ambiente de baixa tolerância ao erro; de acúmulo de tarefas (Souza, 2011, p. 2).

No segmento de gerentes comerciais, que é também o caso de Paula, há muitas falas que mencionam a necessidade de desrespeitar as convicções pessoais para conseguir atingir metas "abusivas". Os relatos fazem referência aos trabalhadores precisarem se humilhar diante dos seus clientes para conseguir a venda de produtos, desvinculados de sua necessidade, chegando ao extremo de venderem produtos para seus próprios familiares, tamanha é a pressão do provável insucesso. Outros relatam, ainda, que são colocados diante da 
pressão "de ir contra suas convicções morais e éticas, para atingirem as metas pré-estabelecidas", explicitando o medo de perderem o emprego, caso não atinjam as metas: "me obrigam a fazer, senão é perder o emprego" (Souza, 2011).

Aliás, essa gestão por metas está generalizada e presente nos mais diversos setores. No comércio, por exemplo, muitas vezes a meta dos vendedores da C\&A é realizar a venda em cinco vezes com juros, em vez de três vezes sem juros; nas Casas Bahia, os trabalhadores devem vender os aparelhos, acompanhados da garantia estendida; até mesmo nas farmácias ou padarias, os funcionários devem vender determinados tipos de produtos em um certo tempo. Também os professores universitários devem cumprir metas para elaborar artigos e orientar alunos. Ou, ainda, as enfermeiras, que são pressionadas a atender uma quantidade cada vez maior de leitos por dia. Como frisam Seligmann-Silva et al. (2011, p. 9), a forma de gestão por metas ou objetivos está presente “em todos os âmbitos da vida humana, individual e coletiva, penetrando, inclusive, em áreas em que os trabalhadores, tradicionalmente, sempre tiveram certa autonomia e independência, como na saúde e na universidade”.

Por isso mesmo, há necessidade de pesquisas que tenham ampla abrangência, tanto do ponto de vista setorial como regional. Nas pesquisas internacionais analisadas ${ }^{5}$, observa-se que seu principal objetivo é compreender de que forma "as condições físicas e organizacionais de trabalho, exposições de risco, as situações dos trabalhadores em relação ao emprego (insegurança, desemprego, inatividade), os recursos (econômicos, cognitivos, psicológicos, sociais), disponíveis ou não para os trabalhadores", contribuem, ao longo do tempo, para manter ou prejudicar a saúde dos trabalhadores (Bahu et al., 2012, p. 26).

Para isso, as pesquisas analisam a relação trabalho-saúde pela percepção do trabalhador de suas condições de trabalho e sua saúde, sendo que muitas delas desenvolveram, inclusive, questionários autoaplicados (como a QVT, K10, SIP, NHP, EWCS e CT). No geral, essas pesquisas buscam compreender a avaliação que o trabalhador faz, na comparação do trabalho que ele tem para realizar (demanda física, mental e emocional) com os meios de que dispóe para realizá-lo (recursos, poderes, capacidades etc.), considerando o contexto social, político e histórico de cada sociedade (Cardoso, 2013c). A fundamentação teórico-metodológica parte das análises realizadas por Karasek e Siegrist (Araújo, 2003), que concluíram que se o trabalhador sofre forte pressão (demanda) mas tem fraca autonomia, fraca sustentação social e ausência de reconhecimento, tal situação constitui fator de risco e tensão no trabalho, gerando insatisfação e favorecendo o adoecimento. Isto é, o adoecimento ocorre quando o trabalhador recebe exigências para as quais não dispõe de
5. As pesquisas analisadas são: Karasek - Job Strain Model; Siegrist - Effort Reward Imbalance (ERI); EWCS/Eurofound - European Working Conditions Surveys; K10 WHO-HPQ - Health Performance Questionnaire; CT - Enquête Conditions de travail; Qualité de Vie au Travail (QVT); General Health Questionnaire (GHQ) - Escala de Goldberg; Santé et l'Itineraire Professional (SIP); Surveillance Medicale des Risques Profissionnels (Sumer); Estev - Santé-travail, Veillisement; Eqcotesst - Enquête Québécoise sur des Conditions de Travail, d'emploi et de Sante et de Securite du Travail; Primera Encuesta Nacional de Empleo, Trabajo, Salud y Calidad de Vida de los Trabajadores y Trabajadoras; Copenhagen Psychosocial Questionnaire (Copsoq); vow-QFT - Questionnaire sur les Facultes de Travail; Nottingham Health Profile (NHP) (Cardoso, 2013c). 
meios suficientes de enfrentamento; quando a empresa realiza uma demanda, seja ela física, mental e/ou emocional, mas não fornece os meios necessários para sua solução (Karasek, 1998).

No contexto atual, de acordo com Daubas-Letourneux e Thébaud-Mony (2002), observa-se uma organização do trabalho que realiza uma "hipersolicitação" aos trabalhadores com a definição de prazos cada vez mais curtos, forte repetição, cadências elevadas, falta de tempo para realização do trabalho, havendo justaposição de riscos denominados clássicos, como os físicos e químicos, e os novos riscos causados pela pressão do tempo e pela exigência de uma produtividade cada vez mais elevada. Por isso mesmo, as pesquisas internacionais sobre trabalho e saúde têm como foco não apenas as questões que poderíamos chamar de "físicas", mas também aquelas relacionadas com os aspectos emocionais e psicológicos, com o pressuposto de que elas não podem ser tratadas separadamente. Muitas dessas pesquisas, aliás, como a CT, a EWCS, a QVT, a Sumer e, sobretudo, a SIP, estão incluindo em seus questionários questões específicas sobre riscos psicossociais no trabalho.

A necessidade de análises para além dos adoecimentos "tradicionais", ou seja, causados por fatores físicos, químicos, biológicos ou mecânicos (Laurrell e Noriega, 1989), fica explícita nas pesquisas citadas e, sobretudo, nos estudos elaborados pelo College d'Expertise em 2011, após diversos suicídios em empresas francesas (Cardoso, 2014). Nesses estudos, os fatores sugeridos para a análise são: a) exigência no trabalho - qualidade, pressão temporal, complexidade e conciliação entre ocupação e vida privada; b) exigência emocional - trabalho em contato com o público, medo no trabalho etc.; c) autonomia e margem de manobra - liberdade para definir quando e como fazer o trabalho, previsibilidade do trabalho, utilização e desenvolvimento de competências profissionais, participação em decisões etc.; d) relação social/ relação no trabalho - apoio social no trabalho, violência no trabalho, assédio, reconhecimento e recompensa, ordens contraditórias etc.; e) conflito de valores e insegurança de emprego e salário.

Por fim, para compreendermos melhor o processo saúde-doença, é necessário ainda analisar as informações mais gerais e "tradicionais" sobre adoecimento e acidentes do trabalho. Tais informações também são reveladoras da situação atual, mesmo que muito limitadas, uma vez que muitas vezes as empresas não reconhecem que o adoecimento está relacionado com o trabalho, mesmo no caso de doenças semelhantes às lesões por esforços repetitivos e distúrbios osteomusculares vinculados ao trabalho (LER/Dort). Daí a extrema importância de ampliar a implantação do Nexo Técnico Epidemiológico 
(NTEP), que permite identificar quais doenças e acidentes estão relacionados com a prática de determinada atividade profissional. É possível, assim, qualificar o acidente de trabalho e demarcar que se trata de benefício acidentário e não previdenciário normal.

Quando o NTEP é identificado, a empresa deve provar que as doenças não derivam da atividade profissional e os acidentes de trabalho não foram causados pelo trabalhador, ou seja, o ônus da prova passa a ser do empregador e não mais do trabalhador. Entretanto, vale ressaltar que, apesar de ser uma grande conquista, o NTEP ainda é muito limitado e nem sempre aplicado pelos peritos do INSS (Maeno, 2009), como pode ser observado no volume de benefícios previdenciários e acidentários ${ }^{6}$ concedidos pelo Ministério da Previdência. Em 2013, por exemplo, é evidente a prevalência da concessão do auxílio-doença ( $88 \%$ dos benefícios) para o acidentário em todas as categorias de Classificação Internacional de Doenças (CID) (MPAS, 2014).

Ao olharmos especificamente para o setor bancário, os "transtornos mentais e comportamentais" são a primeira causa nos benefícios previdenciários e apenas a terceira nos benefícios acidentários. A complexidade para chegar ao diagnóstico dessas doenças e a cultura de culpar o trabalhador que adoece - como aconteceu com Paula, oficialmente licenciada por causa da cirurgia na bexiga - sugerem que poderia ser muito maior o número de trabalhadores recebendo o benefício acidentário.

Assim, vê-se que tanto a conversa direta com os trabalhadores como as pesquisas sobre o tema trabalho e saúde permitem a compreensão não apenas das doenças e dos tipos de acidentes existentes, mas, sobretudo, de suas causas e determinantes. Sem dúvida, é muito importante saber quais são as doenças mais frequentes, os tipos de acidente e em quais setores ocorrem, mas é essencial compreender que o trabalho está levando a essa situação. Afinal, a intenção é que os atores sociais possam atuar nos determinantes/ causas do adoecimento e não apenas em suas consequências. Que possam realmente agir de forma preventiva, tanto do ponto de vista organizacional, como individual, no espaço micro dos locais de trabalho, no espaço meso das negociações coletivas e também no espaço macro da construção de legislação e de políticas públicas.

\section{Pela abordagem do trabalho como determinante do processo saúde-doença}

Esta seção pretende sistematizar as discussões realizadas até o momento ao apresentar alguns fatores essenciais para a compreensão do trabalho como
6. O auxílio-doença éo benefício que o segurado da Previdência Social recebe, mensalmente, ao ficar incapacitado para o trabalho por mais de quinze dias por motivo de doença ou acidente. Pode ser previdenciário, quando não há ou não se consegue provar a relação com o trabalho, ou acidentário, quando está relacionado com a atividade profissional (MPAS, 2014). 
determinante no processo saúde-doença, considerando-se as diversas formas de análise já apresentadas.

Como discutido, inicialmente é necessário comparar situação/meio ambiente/determinantes/exigências/prescrições do trabalho, que podem ser chamadas de "demandas" estabelecidas e definidas pelas empresas. Por outro lado, é fundamental compreendermos quais são os recursos/capacidades/poderes, os respectivos "meios", que as empresas dispõem para que os trabalhadores possam responder às demandas e realizar o trabalho.

As demandas incluem tanto os aspectos físicos como os emocionais e cognitivos, dando conta da realidade das diferentes situações, bem como dos diversos setores da economia. As demandas dividem-se em:

- Físicas - quantidade de trabalho; intensidade; o ritmo (determinado por máquinas, clientes, colegas); metas e objetivos; polivalência; interrupções; pressão temporal.

- Emocionais - tensão com o público; contato com o sofrimento; necessidade de esconder a emoção; de acalmar pessoas; medo durante a realização do trabalho.

- Cognitivas - a complexidade do trabalho; pensar várias coisas ao mesmo tempo; monotonia; aprendizado de coisas novas; grau de concentração; necessidade de seguir normas; grau de responsabilidade; resolução de problemas; concentração; atenção; mudanças constantes (seja em relação aos colegas de trabalho, à hierarquia, à função, aos produtos, às normas, entre outras).

Os meios, por sua vez, abrangem não só elementos do ambiente físico, que continuam a ser importantes, mas também outros tipos de recursos e capacidades que as empresas precisariam dar ao trabalhador, como:

- Autonomia e margem de manobra - para definir a ordem das tarefas, os métodos, a cadência e/ou velocidade, as pausas, os horários, a participação nas mudanças da organização e na definição dos objetivos, os espaços de discussão, a possibilidade de tomar decisões.

- Formação - no que se refere tanto à sua duração quanto ao seu conteúdo.

- Processo e organização do trabalho - previsibilidade no trabalho, eliminação de prescrições contraditórias, informação suficiente para realizar trabalho e/ou saber onde encontrá-las, informações sobre mudanças futuras.

- Relação social e apoio à coordenação e aos colegas de trabalho - apoio 
social e/ou ajuda para resolver problemas, colaboração entre trabalhadores, formas de avaliação, equidade, respeito, sentir-se parte do grupo ou isolado.

- Violência - agressão verbal e/ou física, assédio moral/organizacional e sexual.

- Relação esforço/reconhecimento - que se manifesta nas formas de promoção, de avaliação, no salário etc.

- Tempo de trabalho - no que se refere à duração normal e extra e à sua distribuição.

- Ambiente físico adequado - luz, temperatura, cheiro, limpeza, ausência de barulho, equipamentos adequados, não exposição a agentes químicos/ biológicos, poluição e radiação etc.

- Segurança no emprego - atual e futuro.

A relação entre as "demandas" e os "meios" precisa ser analisada, ainda, em sua dimensão temporal (Rivolier, 1989). O trabalhador pode vivenciar um enorme desequilíbrio entre as demandas e a capacidade de enfrentá-las, por um determinado período de tempo, sem que isso tenha consequências negativas para a sua saúde. No entanto, o mesmo desequilíbrio, se prolongado, pode acarretar reações de estresse e, consequentemente, levar ao adoecimento. Foi o que aconteceu com Paula, que por muitos anos foi submetida à pressão de atender cada vez mais clientes em cada vez mais estados, sem que houvesse aumento da equipe, redução de outras tarefas etc.

Em seguida, devem-se observar as consequências da relação de desequilíbrio entre a demanda e os meios. Uma delas diz respeito aos sentimentos que o trabalhador pode expressar em função do processo ou do resultado do trabalho, de sua situação com os outros trabalhadores, da compatibilização entre sua vida profissional e sua vida privada. Nesse caso, os sentimentos de desequilíbrio entre vida e trabalho; de isolamento e/ou de não pertencimento ao grupo; de conflito de valor; de ausência de prazer; de medo; de que o trabalho não tem valor ou utilidade etc. (Clot, 2010), todos são entendidos como "alarmes" de um futuro adoecimento (Sznelwar, 2011). Por exemplo, os sentimentos: .

Há ainda as consequências para a saúde do trabalhador. De uma forma geral, é essencial captar não apenas as doenças já definidas como "doenças do trabalho" ou "doenças profissionais", mas outros sintomas que também têm sido apontados como resultantes do processo de intensificação do trabalho (Karasek et al., 1998; Seligmann-Silva, 2011). Entre eles, o "mal-estar/sofrimento" (como o cansaço, a ansiedade, o estresse, o desânimo, a dificuldade para dormir, o desespero, a perda de referência), as dores (como dores de cabeça, 
braços, costas, pernas, estômago, tonturas, palpitações etc.) e, enfim, as doenças (LER/Dort, diabetes, problemas cardiovasculares, gastrite/úlcera, hipertensão, depressão, AVC, hipertiroidismo, infertilidade, impotência sexual, síndrome do pânico etc.) e os acidentes de trabalho.

Outra consequência do desequilíbrio entre a demanda e a possibilidade de executá-la refere-se a problemas verificados nos resultados do trabalho, do ponto de vista qualitativo e quantitativo. Tais resultados podem ser observados, por exemplo, na redução da qualidade do produto ou do atendimento ao cliente e na redução da produtividade.

Por fim, como ressaltam Lasfargue e Mathevon (2008), é importante analisar as ações dos trabalhadores diante desse tipo de relação de desequilíbrio: como eles agem e reagem; se pedem ajuda e/ou conversam com os colegas, com a coordenação ou com o comitê de saúde; se vão ao médico do trabalho ou ao médico fora da empresa; se tomam medicamentos e/ou psicotrópicos; se faltam ao trabalho, se tiram férias ou dias de banco de horas; se recorrem a licença-saúde; se, ao contrário, vão trabalhar mesmo doentes ou não se sentindo bem - o chamado presenteísmo -; se pedem demissão, mudam de função, de horário de trabalho; ou, até, se tentam ou praticam o suicídio (Dejours, 2010; Clot, 2010). Apesar de esta ser a última dimensão, na realidade ela está presente em todos os momentos, podendo alterar totalmente o processo saúde-doença.

Isto é, se o trabalhador ao sentir que não está tendo tempo para realizar seu trabalho, ou que seu esforço não está sendo reconhecido conforme avalia que deveria, discutir a situação com o sindicato ou mesmo conversar com seus colegas de trabalho, tal ação poderá ter um impacto totalmente diferente caso ele não tenha a quem recorrer. Da mesma forma, diante de uma doença, o trabalhador pode ter direito a uma licença e se recuperar ou, ao contrário, ter de continuar trabalhando mesmo doente. Dependendo da direção tomada, a ação terá um impacto totalmente distinto no seu processo saúde-doença.

\section{Considerações finais}

A dinâmica das transformações socioeconômicas verificadas nas últimas quatro décadas tem impactado profundamente no trabalho. Há aquelas que são mais visíveis para a sociedade e estão presentes na pauta política de negociação, como o desemprego, a flexibilização do trabalho e a desregulamentação dos direitos trabalhistas. Outras, entretanto, ficam fora desse processo de discussão, justamente por serem menos evidentes. Entre elas, a implantação da gestão "pelo estresse", a crescente intensidade do trabalho, o aumento da pressão, 
do controle, da responsabilização, da competição entre os trabalhadores e da sobrecarga mental e emocional (Cardoso, 2013b). Ou seja, de uma forma geral, a gestão e a organização do trabalho não fazem ou raramente fazem parte da negociação com os trabalhadores, sendo definidas quase unicamente pelo capital. Por isso mesmo, ainda menos visíveis são as implicações dessas mudanças para a vida e a saúde dos trabalhadores, tanto dentro como fora do local de trabalho. Crescem e diversificam-se as formas de sofrimento e as doenças ligadas ao exercício do trabalho: fadiga generalizada, dores musculares, estresse, ansiedade, angústia, depressão, medo, esgotamento profissional (síndrome de Burnout), síndrome do pânico, LER/Dort e problemas cardíacos (Askenazy, 2005; Dal Rosso, 2006; Davezies, 2001; Gollac, 2005; Seligmann-Silva, 2011 e Cardoso 2013b).

Assim, mesmo não sendo o objetivo deste artigo aprofundar uma análise do trabalho e do emprego no contexto atual, ficou evidente que estamos diante de um amplo processo de precarização - apesar de o caso de Paula ser de uma trabalhadora inserida formalmente no mercado de trabalho, com um salário acima da média, com direitos garantidos em convenção coletiva, em um setor de ponta da economia e com nível elevado de formação; ou seja, alguém que faz parte do grupo dos incluídos, conforme Castel (1998). Mesmo assim, sua fala explicita um processo de degradação do trabalho.

Como Franco, Druck e Seligmann-Silva (2010) ressaltam, a precarização do trabalho e do emprego é uma característica que se destaca e abrange diversas dimensões: a precarização dos vínculos de trabalho e das relações contratuais; a precarização da organização e das condições de trabalho; a precarização da saúde dos trabalhadores e das trabalhadoras; a precarização do tecido social; a precarização na natureza da representação e organização coletiva e sindical. O processo geral opõe-se ao que vem sendo chamado de "trabalho sustentável”, como definido na Estratégia Europeia 2020 (Parent-Thirion, 2007). De acordo com essa resolução, a garantia da qualidade do trabalho e do emprego é essencial para um crescimento inclusivo e sustentável. E um dos elementos que contribui para esse crescimento é, justamente, a construção de ambientes de trabalho capazes não apenas de atrair os trabalhadores, mas, sobretudo, de mantê-los em seus empregos, protegendo, ao mesmo tempo, a sua saúde e o desenvolvimento das empresas. Portanto, o trabalho deve ser sustentável tanto do ponto de vista dos indivíduos e de suas famílias como da sociedade e das próprias empresas.

Por isso mesmo o contexto atual explicita a necessidade de construção de novos conhecimentos sobre a relação entre trabalho e saúde, buscando me- 
lhor conhecê-la, explicitá-la e, assim, inseri-la no debate político e social. Para que se possa realmente compreender a relação trabalho-saúde, é importante considerar a vivência do trabalhador sobre carga de trabalho/nível de esforço (físico, cognitivo e emocional) por um determinado período em um contexto organizado localmente e também socialmente, tendo em mente, ainda, os valores, os direitos e as leis vigentes. Por exemplo, pode-se estar em uma sociedade em que o discurso prevalecente explicita o papel determinante do trabalho no processo saúde-doença-acidente ou, ao contrário, um discurso que culpa e responsabiliza o trabalhador individualmente e em função da sua vida privada, influenciando a percepção/avaliação/fala do trabalhador e de sua família. Isso ficou evidente no caso de Paula, ao relatar que sua filha a culpou por não reagir, chegando ao ponto de ter tentado o suicídio. Ou seja, há uma relação de influência recíproca entre a forma como os sujeitos individualmente avaliam sua situação e a maneira como a sociedade trata as questóes (Cardoso, 2014).

Mostramos que, no Brasil, seria de extrema importância uma ampla pesquisa sobre trabalho e saúde do trabalhador, que possibilitasse conhecer melhor a atual organização do trabalho, o processo de intensificação e a saúde do trabalhador, considerando cada um desses elementos, assim como a relação entre eles. Como ressalta Fernex (1998, p. 26), as pesquisas realizadas em diversos países sobre condição de trabalho, que tratam "da descrição de um trabalho real, tal como percebido por um trabalhador, fornecem elementos de apreciação sobre as exigências do trabalho, as condições nas quais ele é exercido e a penosidade que ele pode resultar”. Tais investigações têm contribuído para a visualização do forte processo de intensificação, de precarização e de flexibilização que, apesar de tão presente na sociedade atual, ainda é pouco discutido, negociado ou considerado como objeto de legislação.

O problema é que a explicitação do trabalho como determinante do processo saúde-doença exige questionar sua própria organização e gestão, questões que o capital enxerga como privadas, nas quais nem os trabalhadores nem o Estado deveriam intervir. No caso da sociedade brasileira, essa ausência de discussão fica evidenciada pelos resultados dos acordos ou convenções coletivas, nos quais praticamente não existem cláusulas sobre a organização do trabalho, a gestão, o processo de inovação tecnológica ou a intensificação (Cardoso, 2013b). Mesmo quando a questão da saúde é foco de negociação coletiva, na maior parte das vezes a discussão recai sobre as consequências e não sobre as causas do adoecimento (Cardoso et al., 2011). Uma pesquisa com o referido objetivo respaldaria trabalhadores e seus representantes para pressionar os empregadores a abrirem um debate sobre o assunto. Ao mesmo tempo, contribuiria para que 
os profissionais que trabalham na área da saúde e da saúde do trabalhador incluíssem o trabalho como elemento essencial para a compreensão do processo saúde-doença.

Sabemos que construir novos conhecimentos e informações não garante a inclusão de um tema no debate político. Como ressalta Fernex (1998), ao tornar o olhar capaz de captar e demonstrar a relação entre trabalho e saúde, não podemos deixar de considerar que, assim como as condições de trabalho são objeto de conflito social, as tentativas de avaliação dessas condições também serão objeto desse mesmo conflito. Afinal, não interessa aos empregadores explicitar que a organização e a gestão do trabalho são responsáveis pelo adoecimento do trabalhador.

Ou seja, há duas questões que precisam ser pensadas separadamente, apesar de sua inter-relação. A primeira é criar instrumentos que possibilitem o conhecimento das dimensões do trabalho que estão contribuindo para o adoecimento dos trabalhadores, dentro e fora do local de trabalho. A segunda é, com base nesse conhecimento, produzir normas nos espaços micro, meso e macro que possam regular e impedir que a organização e a gestão atual do trabalho continuem a intensificá-lo e a degradá-lo, a ponto de levar a adoecimentos, acidentes e até suicídios de trabalhadores.

\section{Referências bibliográficas}

ALves, Giovanni. (2011), Trabalho e subjetividade: o espirito do toyotismo na era do capitalismo manipulatório. São Paulo, Boitempo.

Araújo, Tânia Maria et al. (2003), "Estresse ocupacional e saúde: contribuições do modelo demanda-controle". Ciência e Saúde, 4 (8): 12-42.

Askenazy, Philippe. (2005), "Sur les sources de l'intensification". Revue Économique, 2 (56): 217-236.

Askenasy, Philippe; Cartron, Damien; Coninckn, Frédéric de \& GollaC, Michel. (2006), Organisation et intensité du travail. Paris, Octarès.

BAHU, Marlène et al. (2012), "Appréhender les interactions entre la santé et la vie professionnelle et leur éventuel décalage temporel”. Premier Bilan d'une Enquête Innovante: SIP. Document de Travail, Série Sources et Methode, n. 35. Paris, Ministère de l'Économie et des Finances/Ministère des Affaires Sociales et de la Santé/Ministère du Travail, de l'Emploi, de la Formation Professionnelle et du Dialogue Social.

Boisard, Pierre et al. (2002), Temps e travail: l'intensité du travail. Luxemburgo, Eurofound.

Brasil. (2014), Anuário Estatístico da Previdência Social: Benefícios Previdenciários e 
Acidentários. Brasília, Ministério da Previdência e Assistencial Social. Disponível em www.previdencia.gov.br, consultado em 17/9/2014.

Cardoso, Ana Claudia Moreira. (2014), "Indicadores sobre riscos psicossociais no trabalho". In: Silveira, M. A. (org.). Aspectos psicossociais e sustentabilidade em organizaçôes: saúde, segurança e qualidade de vida no trabalho. Campinas, Centro de Tecnologia da Informação Renato Archer.

• (2013a), “Organização e intensificação do tempo de trabalho”. Sociedade e Estado, 28: 351-374.

. (2013b), "Duración, flexibilidad e intendidad: disputas en torno al tiempo de trabajo”. El Cotidiano: Revista de La Realidad Mexicana Actual, 182 (28), nov.-dez. . (2013c), "Organização do trabalho, intensificação e saúde do trabalhador: como apreender essa relação no local de trabalho”. Trabalho apresentado no XIII Encontro Nacional da ABET, Curitiba/UfPR,

. (2009), Tempos de trabalho, tempos de não trabalho: disputas em torno da jornada do trabalhador. São Paulo, Annablume.

Cardoso, Ana Claudia Moreira et al. (2011), “Tempo de trabalho no Brasil: o negociado e o não negociado”. Anais do XII Encontro Nacional da Abet. João Pessoa, Abet.

CASTEL, Robert. (1998), As metamorfoses da questão social: uma crônica do salário. Petrópolis, RJ, Vozes.

CATAldi, Maria José. (2011), Stress no meio ambiente de trabalho. São Paulo, LTr.

CEE - Centre d'Études de l'Emploi. (2001), "Contraintes de temps dans le travail et risques pour la santé en Europe". Quatre Pages, 47, septembre.

Clot, Yves (2010), Le travail à coeur. Paris, La Découverte.

CorrêA, Daniela Lima \& Gilberto, Tadeu. (2006), "Participação dos trabalhadores nos ganhos das empresas: lições da experiência internacional”. Revista de Economia Contemporânea, 2 (10): 357-388.

DAL Rosso, Sadi (2008), Mais trabalho: a intensificação do labor na sociedade contemporânea. São Paulo, Boitempo.

DARES - Direction de l'Animation de la Recherche, des Études e des Statistiques. (2008), "Les facteurs psychosociaux au travail: une évaluation par le questionnaire de Karasek de l'enquête Sumer 2003”. Premières Synthèses: informations, Paris, n. 22, mai.

Daubas-Letourneux, Véronique. \& Thébauid-Mony, Annie. (2002), “Organisation du travail et santé dans l'Union Européene”. Luxemburgo, Eurofound.

Davezies, Philippe (2001), “Charge de travail et enjeux de santé”. Trabalho apresentado no simpósio Négocier la Charge de Travail entre Performance Organisation et Conditions de Travail. Paris, 19 set.

Dejours, Christophe. (2007), Conjurer la violence: travail, violence et santé. Paris, Éditions Payot \& Rivages. 
DuRAND, Jean Pierre. (2004), La chaîne invisible: travailler aujourd'hui: flux tendu et servitude volontaire. Paris, Seuil.

Eurofound - Fundação Europeia para a Melhoria das Condições de Vida e de Trabalho. (2011), Evolução ao longo do tempo: primeiras conclusões do Quinto Inquérito Europeu sobre as Condiçóes de Trabalho. Luxemburgo. Eurofound.

FERneX, Alain. (1998), "Intensité du travail, définition, mesure, évolutions: premiers repérages". Études et Recherche, 169.

Franco, Tânia; DruCK, Graça \& SELIGMANN-SILVA, Edith. (2010), "As novas relações de trabalho, o desgaste mental do trabalhador e os transtornos mentais no trabalho precarizado”. Revista Brasileira de Saúde Ocupacional, 122 (35): 229-248.

GollaC, Michel (2011), "Mesurer les facteurs psychosociaux de risque au travail pour les maîtriser”. Relatório do Collège d'expertise sur le suivi des risques psychosociaux au travail, faisant suite à la demande du Ministre du Travail, de l'Emploi et de la Santé. Paris.

INRS - Institut Nacional de Recherche et de Sécurité. (2010), Le stress au travail. Paris, Dossier.

KARASEK, R. A. et al. (1998), “The Job Content Questionnaire (JCQ): an instrument for internationally comparative assessment of psychosocial job characteristics". Journal of Occupational Health Psychology, 3 (4): 322-355.

LACMAn, Selma \& SzNELWAR, Laerte Idal (orgs.). (2004), Christophe Dejours: da psicopatologia à psicodinâmica do trabalho. Rio de Janeiro, Fiocruz.

Lasfargue, Yves \& Mathevon, Pierre (2008), Qualité de vie et santé au travail: guide pour le management et la négotiation des conditions de trabail dans la société de l'information. Toulouse, Octares.

Laurell, Asa Cristina \& Noriega, Mariano. (1989), Processo de produção e saúde: trabalho e desgaste operário. São Paulo, Hucitec.

LEE, Sangheon et al. (2009), Duração do trabalho em todo o mundo: tendências de jornadas de trabalho, legislação e politicas numa perspectiva global e comparada. Brasília, OIT/ Secretaria Internacional do Trabalho.

Legeron, Patrick (2001), Le stress au travail. Paris, Odile Jacob.

Linhart, Danièle (2005). A desmedida do capital. São Paulo, Boitempo.

MAeno, Maria \& PARARELli, Renata. (2013), “O trabalho como ele é e a saúde mental do trabalhador”. In: Silveira, M. A. (org.). Inovação para o desenvolvimento de organizaçôes sustentáveis: trabalho, fatores psicossociais e ambiente saudável. Campinas, Centro de Tecnologia da Informação Renato Archer.

Mathieu, René \& Gorgeu, Armelle. (s. d.), O trabalho operário é sustentável? Uma ilustração na indústria automotiva na França. Paris, CNRS (mimeo.).

Metzer, Jean Luc. (2011), “Mudança permanente: fonte de penosidade no trabalho?”. Revista Brasileira de Saúde Ocupacional, 123 (36): 12-24. 
PaOli, Pascal \& Merllié, Damien. (2001), “Troisième enquête européene sur les conditions de travail 2000”. Luxemburgo, Eurofound.

PArent-Thirion, Agnes et al. (2007), "Quatrième enquête européenne sur les conditions de travail”. Luxemburgo, Eurofound.

PEZÉ, Marie. (2008), Ils ne mouraient pas tous mais tous étaient frappés. Paris, Pearson.

PinA, José Augusto. (2012), Intensificação do trabalho e saúde dos trabalhadores na indústria automobilística: estudo de caso na Mercedes Benz do Brasil. São Bernardo do Campo. Tese de doutorado, Rio de Janeiro, Escola Nacional de Saúde Pública/Fiocruz.

PINA, José Augusto \& STOTZ, Eduardo Navarro. (2011), "Participação nos lucros ou resultados e o banco de horas: intensidade do trabalho e desgaste operário”. Revista Brasileira de Saúde Ocupacional, 123 (36): 162-176.

Rivolier, Jean. (1989), L’homme stressé. Paris, Presses Universitaires de France.

Seligmann-Silva, Edith. (2011), Trabalho e desgaste mental: o direito de ser dono de si mesmo. São Paulo, Cortez.

SELIGMANN-Silva, Edith et al. (2010a), "Saúde do trabalhador no início do século XXI". Revista Brasileira de Saúde Ocupacional, 122 (35): 185-186.

SeligmanN-Silva, Edith et al. (2010b), "Saúde do trabalhador no início do século XXI”. Revista Brasileira de Saúde Ocupacional, 123 (36), jul.-dez.

Souza (2011), "Pesquisa: o impacto da organização e do ambiente de trabalho bancários na saúde física e mental da categoria”. Seminário Internacional Saúde dos Bancários. São Paulo, Sindicato dos Bancários.

SzNelWAR, Laerte Idal (org.). (2011), Saúde dos bancários. São Paulo, Editora Gráfica Atitude.

VALEYRE, Antoine. (2007), “Les conditions de travail des salariés dans l'Union Européene à quinze selon fes formes d'organization”. Travail et Emploi, 112: 35-47.

92 Tempo Social, revista de sociologia da USP, v. 27, n. 1 


\section{Resumo}

O trabalho como determinante do processo saúde-doença

Pretende-se analisar como, no contexto atual, as condições organizacionais e físicas do trabalho, as situações e as relações de trabalho e as formas de gestão estão determinando e contribuindo para o adoecimento dos trabalhadores. Para compreender uma relação tão complexa, discute-se a necessidade de empreender olhares diferentes e complementares. Assim, a partir do depoimento de uma trabalhadora adoecida pelo trabalho, pretende-se construir um diálogo com alguns estudos teóricos que tratam da relação entre a atividade do trabalho e a saúde do trabalhador, sendo analisadas, ainda, as informações teórico-metodológicas de pesquisas internacionais que têm como foco a saúde do trabalhador. Palavras-chave: Saúde do trabalhador; Saúde mental; Organização do trabalho; Assédio organizacional; Setor bancário.

\section{Abstract}

Work as a determining factor in the health-sickness process

The article seeks to analyse how, in the current context, the organizational and fiscal conditions of work, labour situations and relations, and forms of management all determine and contribute to worker sickness. In order to comprehend this complex relationship, the text discusses the need to explore different and complementary viewpoints. Based on the testimony of a worker made sick by work, therefore, I look to construct a dialogue with a number of theoretical studies that treat the relation between the activity of work and worker health, as well as analysing the theoretical-methodological information provided by international research into workers' health.

Keywords: Health worker; Mental health; Organization of work; Workplace harassment; Banking sector.

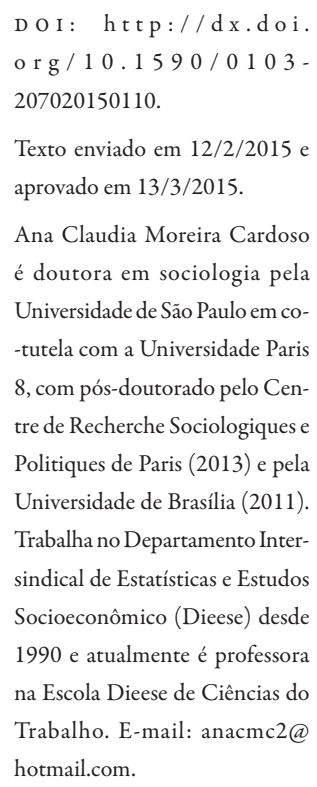


Vol27n1.indd 94 